\title{
Leptin treatment of patients with anorexia nervosa? The urgent need for initiation of clinical studies
}

\author{
Johannes Hebebrand • Özgür Albayrak
}

Published online: 31 January 2012

(C) Springer-Verlag 2012

The core symptomatology of anorexia nervosa can be conceptualized as the intertwining of the primary behaviors with the psychological and physical consequences of starvation $[1,2]$. The onset of this eating disorder is seemingly unspectacular: similar to many other females of the respective age group most patients strive to lose weight by dieting, some additionally increase their physical activity; a not well specified percentage of patients starts off with weight loss unrelated to the desire to lose weight, such as a depressed mood or obsessive-compulsive behaviors related to food and its intake. While AN patients as a group have elevated rates of premorbid psychopathology, an individual patient may present without a history of mental problems. Indeed, patients are frequently characterized as well (or even overly) adjusted prior to initial weight loss.

After weight loss sets in, patients are rewarded internally by for instance a positive experience of control over their eating behavior and their body weight and potentially externally by positive remarks of peers and family members. At the same time the physiological response to a reduced energy intake sets in, which in its continuation entails the well-known symptoms of starvation encountered in acutely ill patients. This intertwining of the primary behaviors leading to initial and prolonged weight loss and

J. Hebebrand $(\varangle) \cdot$ Ö. Albayrak

Department of Child and Adolescent Psychiatry,

University of Duisburg-Essen, Virchowstr. 174,

45147 Essen, Germany

e-mail: Johannes.Hebebrand@uni-due.de the ongoing adaptation to starvation in total result in the characteristic clinical phenotype upon presentation of a patient, which includes somatic, cognitive and behavioral symptoms. A patient at this stage will potentially state that the initial desire to lose weight was replaced by an urge or compulsion to continue to do so ultimately leading to a sense of loss of control over energy intake and body weight.

The therapeutic armamentarium available for AN patients must be considered as meager. Weight reconstitution is considered as paramount; inpatient treatment by an experienced team is required if underweight and starvation symptoms have resulted in a critical condition (http:// www.nice.org.uk/nicemedia/live/10932/29220/29220.pdf). Both psychotherapeutic and psychopharmacological trials have been hampered by the high drop-out rates characteristic of AN patients. A recent study that compared specialist supportive clinical management, cognitive behavior therapy and interpersonal psychotherapy revealed no significant differences on any pre-selected primary, secondary or tertiary outcome measures among the three psychotherapies after a mean follow-up of 6.7 years [3]; specialist supportive clinical management led to a more rapid response than interpersonal psychotherapy. Antidepressants and in particular selective serotonin reuptake inhibitors have not proven beneficial for treating the disorder itself or the frequent comorbid depression. There is evidence that olanzapine is helpful during the acute phase of AN [4]. The treatment costs for AN are high; in Germany it was estimated that the total direct treatment costs amounted to 195 million euros in 1999 which implied mean annual costs per patient of approximately 5,300 euros [5].

In light of these meager and costly therapeutic options it is our obligation to be on the lookout for novel treatments. We and others have proposed treating acutely ill AN patients with leptin for more than a decade; nevertheless, 
not a single patient has as yet been treated with this hormone. This is all the more surprising as recombinant leptin is available. Furthermore, the risk of adverse side effects appears manageable if initially low dosages are used within an inpatient setting that allows a close clinical monitoring.

In 1994 Jeff Friedman and coworkers [6] at Rockefeller University cloned the obese gene leading to the discovery of the hormone leptin (named after the Greek word leptos for thin). The discovery of leptin was paramount for our current understanding of body weight regulation: the hormone, which is mainly synthesized in adipocytes, signals the fat mass (and thus the energy content of the fat depot) of the body to the brain; via specific receptors in the hypothalamus this signal entails the release of anorexigenic (pro-opiomelanocortin, cocaine and amphetamine regulated transcript) and impedes the release of orexigenic (neuropeptide Y, agouti-related peptide) peptides, which in turn initiate a signaling cascade which functions to regulate energy intake and expenditure. Leptin and other hormones such as ghrelin are responsible for the more or less tight regulation of human body weight $[7,8]$.

The obese mouse originally served to localize the respective gene; the phenotype of this natural autosomal recessive mutant encompasses hyperphagia and extreme obesity; nevertheless, starvation symptoms such as hypothalamic infertility figure prominently in the respective phenotype. Subsequent animal studies have led to the concept that the major function of leptin is to adapt an organism to a reduced caloric intake and conditions of starvation [9]. If calorie intake is restricted over prolonged periods of time, fat mass is reduced leading to a lowered leptin synthesis in adipocytes and reduced serum levels. Once the leptin level drops below critical thresholds, the hypothalamus-pituitary-gonadal, -thyroid, -adrenal and growth hormone axes are down- or up-regulated. These neuroendocrine alterations subsequently entail the development of starvation symptoms including amenorrhea in females. Because high circulating leptin levels in subjects with obesity do not lead to a (sufficient) curtailment of energy intake, the concept of leptin resistance has been invoked.

The first study of leptin levels in patients with AN revealed that some patients had undetectable levels upon use of the respective ELISA [10]. Subsequent work clearly underscored that hypoleptinemia is a hallmark of acute AN; the levels are well below those of age-matched healthy females [11, 12]. Healthy underweight females have sufficient leptin levels to prevent the initiation of the physiological adaptation to starvation; in AN patients subphysiological levels are the trigger for this adaptation. A proof of concept was provided by a study of eight females with hypothalamic amenorrhea due to strenuous exercise or low weight (unfortunately the investigators did not report on the lifetime occurrence of eating disorders) who were treated with recombinant leptin over a 3-month period. In three females an ovulatory cycle occurred; others also showed evidence for an improved reproductive function [13]. A subsequent randomized, double-blinded placebocontrolled trail of 36 weeks demonstrated similar beneficial effects [14].

An important clinical symptom in AN is hyperactivity which can be so severe as to hamper treatment and weight gain; in such cases neuroleptic medication is frequently used to reduce activity levels. In rats, caloric restriction leads to hyperactivity; running wheel activity increases by $300-400 \%$; if recombinant leptin is applied throughout the caloric restriction phase the development of hyperactivity is completely suppressed. In addition, once hyperactivity has developed leptin can be used to successfully reduce activity $[15,16]$. In AN patients, the relationship between activity and serum leptin levels has been shown to correspond to an inverted $U$ [17]. If levels are exceedingly low (e.g., in patients with a body mass index below $13 \mathrm{~kg} / \mathrm{m}^{2}$ ), activity levels are lower than those of patients who have somewhat higher leptin levels-in rats motor activity also declines prior to death.

It has been hypothesized that the hypoleptinemia in AN patients may also contribute to the frequent comorbid depression [17]. Clinicians experience that the mood of a patient improves during weight restoration-potentially as a consequence of an increased leptin synthesis. Interestingly, leptin-deficient $o b / o b$ mice show more severe depressive behavior in the forced swim test than normal mice, and leptin administration substantially ameliorates this depressive behavior [18].

After the discovery of leptin, Rockefeller University subsequently licensed the respective patent to Amgen. In 2006 Amylin acquired the exclusive rights to the leptin molecular franchise and program from Amgen. Amylin's license includes exclusive rights to the leptin intellectual property developed by Amgen as well as intellectual property Amgen originally licensed from Rockefeller University (http://www.wikinvest.com/stock/Amylin_Pharmaceuticals_ (AMLN)/Leptin).

During the last 12 years, ample experience was gathered with recombinant methionyl human leptin (metreleptin) as a drug in systematic clinical trials of patients with obesity or lipodystrophy. Leptin-deficient individuals dramatically lose weight upon leptin treatment [19]. Leptin monotherapy in nonleptin-deficient obese individuals was shown to reduce body weight only moderately [20, 21]. Most pharmacological trials using metreleptin in the treatment of obesity have excluded individuals with metabolic dysregulation. However, interesting insights into the metabolic changes that follow metreleptin therapy stem from clinical trials in lipodystrophy. This rare disorder is characterized 
by full or partial loss of adipose tissue, entailing, e.g., insulin resistance, hypertriglycinemia, and diabetes that subsequently lead to severe complications, such as acute pancreatitis, liver cirrhosis and atherosclerosis. Despite heterogeneous causes for lipodystrophy (e.g., genetic or auto-immune-related mechanisms, idiopathic forms), the hallmark of all forms of this disorder is a relative leptin deficiency [22]. Indeed, subcutaneous substitution therapy with metreleptin was shown to significantly improve the metabolic profile (e.g., HbAlc, triglycerides, liver enzymes) of lipodystrophic patients in an ongoing long-term clinical trial [23].

Thus, metreleptin has repeatedly been proven to be effective and comparatively safe in various study populations of subjects with obesity and lipodystrophy. Common adverse effects included nausea and injection side effects upon subcutaneous application, which were mostly classified as mild to moderate and which showed a tendency to decrease over time [24].

Attempts to initiate treatment of an AN patient with recombinant leptin have not been successful due to the reluctance of companies to pursue the use of leptin in this eating disorder. As such, a potentially valuable mode of treatment is not being examined in our patients, whose hypoleptinemia a priori make them highly likely candidates to show improvement upon treatment with recombinant leptin. Leptin could potentially ameliorate hyperactivity and depression in acutely ill patients and reproductive function after weight gain. It also appears fascinating to speculate on beneficial effects on other starvation-related psychopathological features of acutely ill patients including obsession with food, weight and body shape. Obviously, side effects need to be considered including a potential loss of appetite and subsequent weight loss; however, we deem both of these concerns as negligible in closely monitored inpatients. Undoubtedly, leptin treatment cannot replace the need to increase body weight. It is worthwhile speculating that the positive effects on starvation-related psychopathology and behaviors could render patients more amenable to weight regain and thus shorten the current lengthy weight regain phase. Leptin may lead to an increase of the sympathetic tone which might pose serious problems in emaciated individuals. As a consequence, the initial cases would have to be monitored very closely as inpatients; low dosages of recombinant leptin should be applied to assess the initial reaction of a starved human organism. For ethical considerations a patient should be $\geq 18$ years old, she must be able to understand the potential risks. We need to lobby on behalf of our patients. If you agree that studies are warranted to assess the potentially beneficial effects of leptin in AN patients, please send us a mail.

\section{References}

1. Hebebrand J, Casper R, Treasure J, Schweiger U (2004) The need to revise the diagnostic criteria for anorexia nervosa. J Neural Transm 111(7):827-840

2. Hebebrand J, Bulik CM (2011) Critical appraisal of the provisional DSM-5 criteria for anorexia nervosa and an alternative proposal. Int J Eat Disord 44(8):665-678

3. Herpertz-Dahlmann B, Hebebrand J (2011) Assessment and treatment of eating disorders and obesity. In: Martin A, Scahill L, Charney DS, Leckman JF (eds) Pediatric psychopharmacology: principles and practice, Oxford, New York, pp 570-584

4. Carter FA, Jordan J, McIntosh VV, Luty SE, McKenzie JM, Frampton CM, Bulik CM, Joyce PR (2011) The long-term efficacy of three psychotherapies for anorexia nervosa: a randomized, controlled trial. Int J Eat Disord 44(7):647-654

5. Krauth C, Buser K, Vogel H (2004) Die gesellschaftlichen Kosten von Essstörungen-Krankheitskostenanalysen für Anorexia und Bulimia nervosa. In: Vogel H, Wasem J (eds) Gesundheitsökonomie in Psychotherapie und Psychiatrie. Schattauer, Stuttgart, pp 153-173

6. Zhang Y, Proenca R, Maffei M, Barone M, Leopold L, Friedman JM (1994) Positional cloning of the mouse obese gene and its human homologue. Nature 372(6505):425-432

7. Friedman JM, Halaas JL (1998) Leptin and the regulation of body weight in mammals. Nature 395:763-770

8. Morton GJ, Cummings DE, Baskin DG, Barsh GS, Schwartz MW (2006) Central nervous system control of food intake and body weight. Nature 443:289-295

9. Ahima RS, Prabakaran D, Mantzoros C, Qu D, Lowell B, Maratos-Flier E, Flier JS (1996) Role of leptin in the neuroendocrine response to fasting. Nature 382(6588):250-252

10. Hebebrand J, van der Heyden J, Devos R, Köpp W, Herpertz S, Remschmidt H, Herzog W (1995) Plasma concentrations of obese protein in anorexia nervosa. Lancet 346(8990):1624-1625

11. Hebebrand J, Muller TD, Holtkamp K, Herpertz-Dahlmann B (2007) The role of leptin in anorexia nervosa: clinical implications. Mol Psychiatry 12:23-35

12. Föcker M, Timmesfeld N, Scherag S, Bühren K, Langkamp M, Dempfle A, Sheridan EM, de Zwaan M, Fleischhaker C, Herzog W, Egberts K, Zipfel S, Herpertz-Dahlmann B, Hebebrand J (2011) Screening for anorexia nervosa via measurement of serum leptin levels. J Neural Transm 118(4): 571-578

13. Welt CK, Chan JL, Bullen J, Murphy R, Smith P, DePaoli AM, Karalis A, Mantzoros CS (2004) Recombinant human leptin in women with hypothalamic amenorrhea. N Engl J Med 351(10): 987-997

14. Chou SH, Chamberland JP, Liu X, Matarese G, Gao C, Stefanakis R, Brinkoetter MT, Gong H, Arampatzi K, Mantzoros CS (2011) Leptin is an effective treatment for hypothalamic amenorrhea. Proc Natl Acad Sci USA 108(16):6585-6590

15. Exner C, Hebebrand J, Remschmidt H, Wewetzer C, Ziegler A, Herpertz S, Schweiger U, Blum WF, Preibisch G, Heldmaier G, Klingenspor M (2000) Leptin suppresses semi-starvation induced hyperactivity in rats: implications for anorexia nervosa. Mol Psychiatry 5(5):476-481

16. Hebebrand J, Exner C, Hebebrand K, Holtkamp C, Casper RC, Remschmidt H, Herpertz-Dahlmann B, Klingenspor M (2003) Hyperactivity in patients with anorexia nervosa and in semistarved rats: evidence for a pivotal role of hypoleptinemia. Physiol Behav 79(1):25-37

17. Holtkamp K, Herpertz-Dahlmann B, Hebebrand K, Mika C, Kratzsch J, Hebebrand J (2006) Physical activity and restlessness 
correlate with leptin levels in patients with adolescent anorexia nervosa. Biol Psychiatry 60(3):311-313

18. Yamada N, Katsuura G, Ochi Y, Ebihara K, Kusakabe T, Hosoda K, Nakao K (2011) Impaired CNS leptin action is implicated in depression associated with obesity. Endocrinology 152(7):2634 2643

19. Farooqi IS, Jebb SA, Langmack G et al (1999) Effects of recombinant leptin therapy in a child with congenital leptin deficiency. N Engl J Med 341:879-884

20. Heymsfield SB, Greenberg AS, Fujioka K, Dixon RM, Kushner R, Hunt T, Lubina JA, Patane J, Self B, Hunt P, McCamish M (1999) Recombinant leptin for weight loss in obese and lean adults: a randomized, controlled, dose-escalation trial. JAMA 282(16):1568-1575
21. Hukshorn CJ, Saris WH, Westerterp-Plantenga M et al (2000) Weekly subcutaneous pegylated recombinant native human leptin (PEG-OB) administration in obese men. J Clin Endocrinol Metab 85:4003-4009

22. Garg A (2004) Acquired and inherited lipodystrophies. N Engl J Med 350:1220-1234

23. Chan JL, Lutz K, Cochran E, Huang W, Peters Y, Weyer C, Gorden P (2011) Clinical effects of long-term metreleptin treatment in patients with lipodystrophy. Endocr Pract 8:1-31

24. Tam CS, Lecoultre V, Ravussin E (2011) Novel strategy for the use of leptin for obesity therapy. Expert Opin Biol Ther 11(12): $1677-1685$ 